\title{
New data on isotopic signature of the thermal groundwaters from Kuldur spa (Russia)
}

\author{
L.LYAMINA ${ }^{1}$, N.KHARITONOVA ${ }^{12}$, G.CHELNOKOV ${ }^{2}$, \\ I.BRAGIN $^{2}$, H.NAKAMURA $^{34}$, H. IWAMORI $^{4}$, \\ N.MORIKAWA ${ }^{3}$, E.CHEBIKIN ${ }^{5}$ \\ ${ }^{1}$ Lomonosov Moscow State University, Moscow, 119991, \\ GSP-1, 1 Leninskiye Gory, ( tchenat@mail.ru) \\ ${ }^{2}$ Far East Geological Institute FEB RAS, 690022, \\ Vladivostok, Prospect 100letya 159, (geowater@mail.ru) \\ ${ }^{3}$ Geological Survey of Japan, National Institute of Advanced \\ Industrial Science and Technology \\ ${ }^{4}$ Japan Agency for Marine-Earth Science and Technology \\ ${ }^{5}$ Limnological Institute Siberian Branch of RAS, Russia
}

The research is based on the results of field works that was conducted in the period 2014-2015 and 2018-2019.

The purpose of this work is to study the isotopic signature of nitric thermal groundwaters from Kuldur spa and characterize their circulation processes. For solving this task, multiple isotopes $\delta \mathrm{D}, \delta^{18} \mathrm{O},{ }^{3} \mathrm{H},{ }^{3} \mathrm{He} /{ }^{4} \mathrm{He},{ }^{4} \mathrm{He} /{ }^{20} \mathrm{Ne}$, $\delta^{13} \mathrm{C},{ }^{234} \mathrm{U} /{ }^{238} \mathrm{U}$ together with geothermometer calculation were utilized.

The thermal waters were sampled for isotopic analysis. Samples for ${ }^{18} \mathrm{O}, \mathrm{D},{ }^{13} \mathrm{C},{ }^{234} \mathrm{U} /{ }^{238} \mathrm{U},{ }^{15} \mathrm{~N}$ analysis were not filtered and placed in a special dish. The sample volume isotope ${ }^{234} \mathrm{U} /{ }^{238} \mathrm{U}$ was 1,5 liters, for ${ }^{13} \mathrm{C} 5$ liters. In the samples for analysis of isotope ${ }^{13} \mathrm{C}$, the $\mathrm{Ba}(\mathrm{OH})_{2}$ was added for precipitating $\mathrm{BaCO}_{3}$ for its further analysis.

The $\delta^{18} \mathrm{O}$ and $\delta \mathrm{D}$ are parallel with GMWL showing that the recharge source of thermal water is local meteoric precipitation. Value of ${ }^{3} \mathrm{H}$ are very low up to $0.7 \mathrm{TE}$ which indicate the long circulation time and also confirm no dilution of deep thermal waters with shallow cold water.

The obtained data on the isotopic composition of ${ }^{3} \mathrm{He} /{ }^{4} \mathrm{He}$ and ${ }^{4} \mathrm{He} /{ }^{20} \mathrm{Ne}$ of dissolved gases let assume that the helium refers to the crustal origin $\left({ }^{3} \mathrm{He} /{ }^{4} \mathrm{He}\right.$ from $2.86 \times 10-7$ for the well 3-87 and 4.12×10-7 for the well 2-87).

The $\delta^{13} C_{\text {DIC }}$ values vary from -30 to $-18.1 \%$ and testify on the biogenic origin of carbonate specimens.

In 2018, samples were taken for the isotope ${ }^{15} \mathrm{~N}$ to determine the genesis of nitrogen. According to the data obtained from the well $1-87 \delta^{15} \mathrm{~N}=0.1 \%$, which indicates the air origin of nitrogen in thermal waters.

The ${ }^{234} \mathrm{U} /{ }^{238} \mathrm{U}$ dating, the circulation time of the studied thermal groundwater is at about 400,000 years.

The reported study was funded by RFBR according to the research projects 18-05-00445 and 19-55-50002. 